\title{
Fluid Dynamics Simulation of High Speed Jet under Distinct Initial Input Velocities
}

\author{
Jie Gong1, Wen Xia1 ${ }^{*}$, Qiang Zhang' ${ }^{2}$ Fan Zhang1, Yanyun Lin'1, Jihua Li1 \\ ${ }^{1}$ Agricultural Product Processing Research Institute at Chinese Academy of Tropical Agricultural Sciences, Chinese Agricultural \\ Ministry Key Laboratory of Tropical Crop Products Processing, Zhanjiang, China \\ ${ }^{2}$ School of Mechanical Engineering, Liaoning Technical University, Fuxin, China \\ Email: *xiawensg@163.com
}

How to cite this paper: Gong, J., Xia, W., Zhang, Q., Zhang, F., Lin, Y.Y. and Li, J.H. (2018) Fluid Dynamics Simulation of High Speed Jet under Distinct Initial Input Velocities. World Journal of Engineering and Technology, 6, 1-7.

https://doi.org/10.4236/wjet.2018.63B001

Received: April 2, 2018

Accepted: August 6, 2018

Published: August 9, 2018

\begin{abstract}
The aim of this study is to execute the fluid dynamics simulation of high speed jet under distinct input velocities (i.e., 114.1, 142.4, 165.6, 186.2 and $286.9 \mathrm{~m} / \mathrm{s}$ ). In particular, this study focuses on the impact velocity and velocity of two-phase flow (gas-liquid). Firstly, the three-dimensional geometric model of high speed jet is established on the basis of the actual operational conditions. Next, the unstructured grids of high speed jet are generated by means of ANSYS Fluent. Finally, the fluid dynamics simulation of high speed jet is implemented by using Fluent. The simulation results show that when the input velocity of the liquid increases, the impact velocity declines sharply, while according to the Bonuli law of conservation of energy, the impact effect on the device shows exponential growth with increasing input velocity. In addition, the relationship between the impact velocity and the input velocity and the relationship between the impact effect on the device and the input velocity are achieved, which could provide certain theoretical guidance for predicting the working pressure and velocity of high speed jet based on real input velocity.
\end{abstract}

\section{Keywords}

Fluid Dynamics, ANSYS Fluent, Input Velocity, Impact Pressure, Impact Velocity, Impact Effect

\section{Introduction}

$15 \%$ - $45 \%$ of Starch is crystalline regions, which usually limits the application in food industry. In order to enlarge its application field and obtain some functional properties in accordance with the requirement of specific industrial applica- 
tions, various treatments (physical, chemical and enzymatic) on starch have been investigated [1]. Among those methods, physical treatments have been considered as good and environmental technique in modifying starches. High-pressure technology with combination of high pressure, high shear and cavitation, has been considered as a useful technique in modifying starches among various physical modification treatments [2].

We have investigated the effect of high speed jet on the physical properties of tapioca starch. The results provided the basic information on the physical properties of tapioca starch treated at different pressures and indicated the potential possibility of high speed jet for starch modification. Also, we successful execute the preparation of nanostarches by high speed jet, which would expand its applications in food or non-food system [3] [4] [5] [6]. In addition, our previous research has shown the changes of the working pressure and the working velocity of the high speed jet, which are affected by the input pressure [7]. As the complicated condition of the high speed jet, our previous research does not analyze the change of the impact effect. Therefore, this study is aiming at finding out how different input velocities affect the impact velocity and impact effect. In this study, the input velocity (i.e., 114.1, 142.4, 165.6, 186.2 and $286.9 \mathrm{~m} / \mathrm{s}$ ) is chosen by our previous research, which represents the specific working pressure [8].

\section{Computational Fluid Dynamics Modeling}

\subsection{Geometry Model and Mesh Generation}

High speed jet is a novel device, which uses water to generate powerful pressure and high speed. Although it is widely used in many aspects, including agricultural machinery, industrial machinery and construction machinery, it is rarely used in food processing. As the ANSYS Fluent is widely used in numerical simulation, especially in the field of fluid, heat transfer chemical reaction and engineering, it is used to simulate the reaction of the model under different input velocities in this study [7] [9]-[14]. The geometric model is established in Figure 1. It is separated into two parts, which is similar to the reality. One is the spray nozzle, where the liquid is released, and the other is the computational domain.

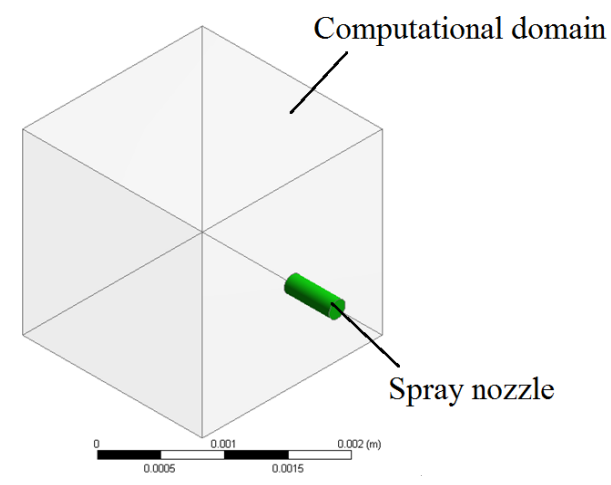

Figure 1. Geometric model. 
Compared with structured grids unstructured grids allow the calculation of flows in or around geometrical features of arbitrary complexity without having to spend a long time on mesh generation and mapping. Therefore, in this study, the unstructured grids of the geometric model are generated by means of ANSYS Fluent.

\subsection{Boundary Conditions}

According to the actual device of the high speed jet, the computational domain and the spray nozzle diameter of the analytical model are $2 \mathrm{~mm}$ and $0.18 \mathrm{~mm}$. The input velocities are $114.1,142.4,165.6,186.2$ and $286.9 \mathrm{~m} / \mathrm{s}$ respectively. The only input of the model is the nozzle. As the high velocity of the flow from then nozzle, there is almost no loss of the potential energy. Therefore, the impact energy is equal to the kinetic energy theoretically. To achieve the actual results, which would not be affected by outlet conditions, the outlet is set on the top and the bottom of the computational model.

\section{Simulation Results Analysis}

\subsection{Influences of Input Velocity on the Impact Velocity}

Figure 2 shows the maximum impact velocities of high speed jet under different
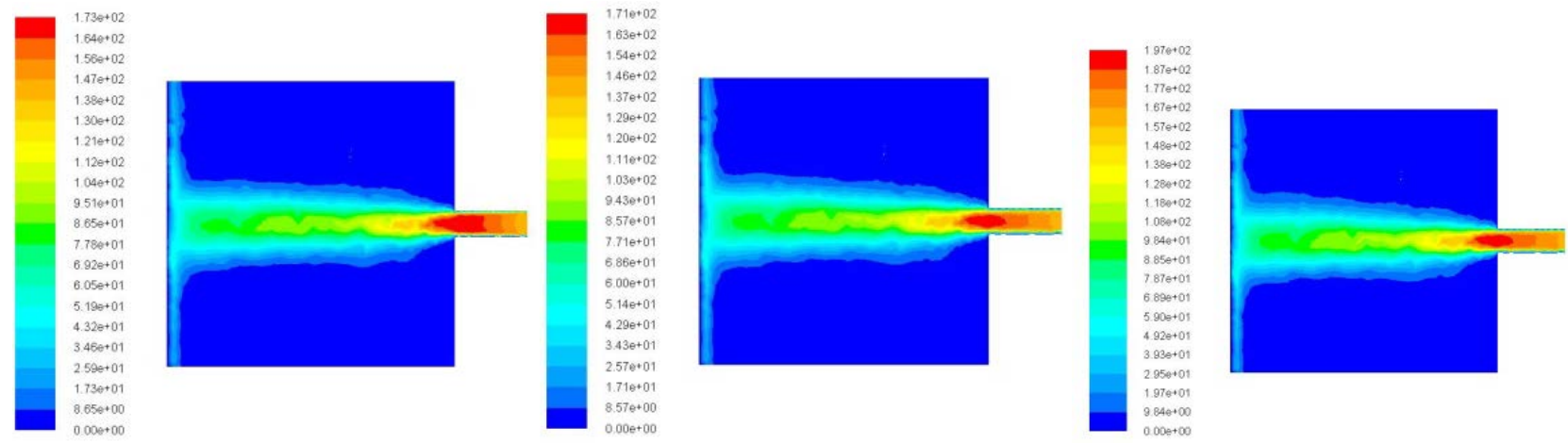

(a)

(b)

(c)

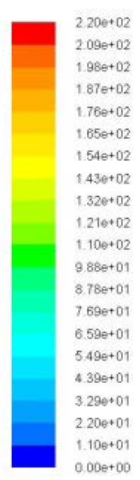

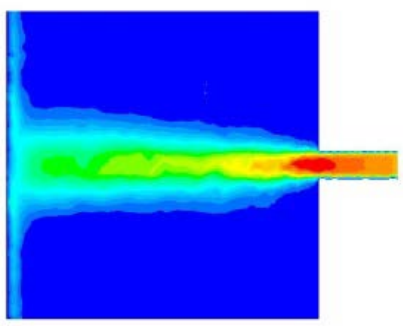

(d)

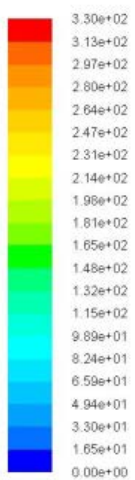

$0.000+00$

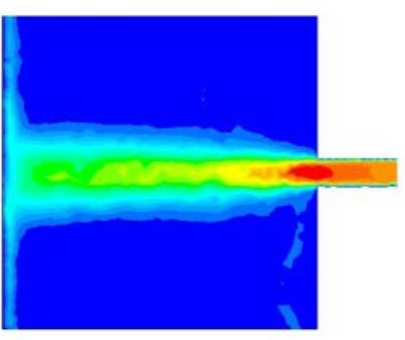

(e)

Figure 2. Impact velocity of high speed jet under different input velocity (a) v=114.1 m/s; (b) v = $142.4 \mathrm{~m} / \mathrm{s} ;(\mathrm{c}) \mathrm{v}=165.6 \mathrm{~m} / \mathrm{s} ;(\mathrm{d})$ $\mathrm{v}=186.2 \mathrm{~m} / \mathrm{s} ;(\mathrm{e}) \mathrm{v}=286.9 \mathrm{~m} / \mathrm{s}$. 
input velocities (114.1, 142.4, 165.6, 186.2 and $286.9 \mathrm{~m} / \mathrm{s}$ ). According to Figure 2 , although there is no loss of the input velocity in the spray nozzle, it is notable that the impact velocity of high speed jet decreases swiftly after the liquid flows in. In addition, the maximum impact velocity is at the entrance of the nozzle.

Likely, the impact velocity of flows at the exit of the nozzle is the impact working velocity of high speed jet. The impact working velocity of high speed jet under different input velocity is indicated in Figure 3. With the rise in input velocity, the impact working velocity of high speed jet increases from 86.5 to 181.3 $\mathrm{m} / \mathrm{s}$ between the input velocity of 114.1 and $286.9 \mathrm{~m} / \mathrm{s}$.

\subsection{Influences of Input Velocity on the Velocity of Two-Phase Flow (Gas-Liquid)}

Figure 4 shows the velocity of two-phase flow (gas-liquid) of high speed jet under different input velocity $(114.1,142.4,165.6,186.2$ and $286.9 \mathrm{~m} / \mathrm{s}$ ). According to Figure 4, as the input velocity increases, the velocity of two-phase flow (gas-liquid) of high seed jet soars as well. In addition, the maximum velocity of two-phase flow (gas-liquid) is at the entrance of the nozzle.

Similarly, as the computational domain is relatively small and the inlet velocity of flows is quick, according to the Bonuli law of conservation of energy, the relationship between the inlet velocity of high speed jet and impact effect is achieved, as demonstrated in Equation (1).

$$
W=\frac{1}{2} m v_{\text {input }}^{2}-\frac{1}{2} m v_{\text {impact }}^{2} .
$$

where $S$ is the area of the inlet nozzle.

Specifically, Figure 5 shows that the impact effect on the device shows exponential growth from 804 to $184.4 \mathrm{~J}$ with the rise in input velocity.

\section{Conclusions}

Depending on the fluid dynamics simulation implemented in this study, the

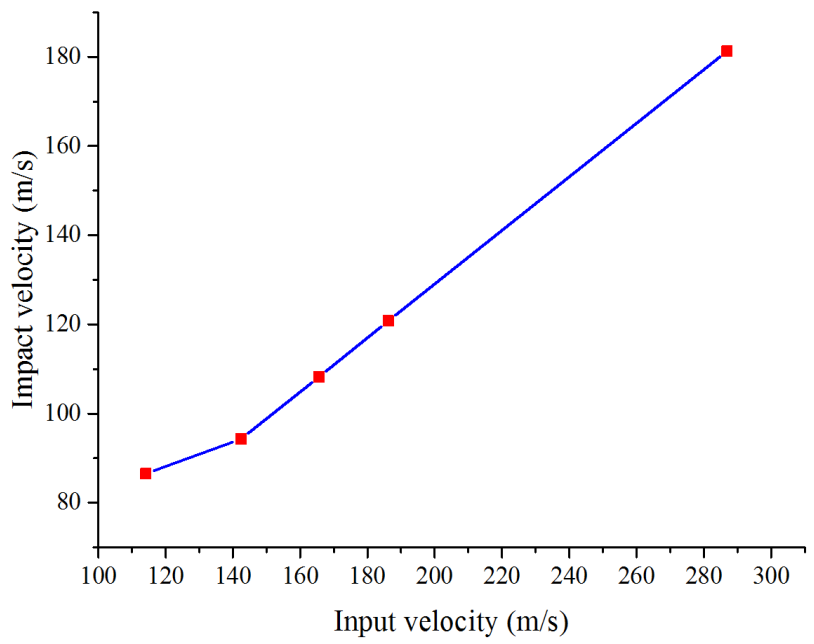

Figure 3. Plot of impact velocity versus input velocity. 


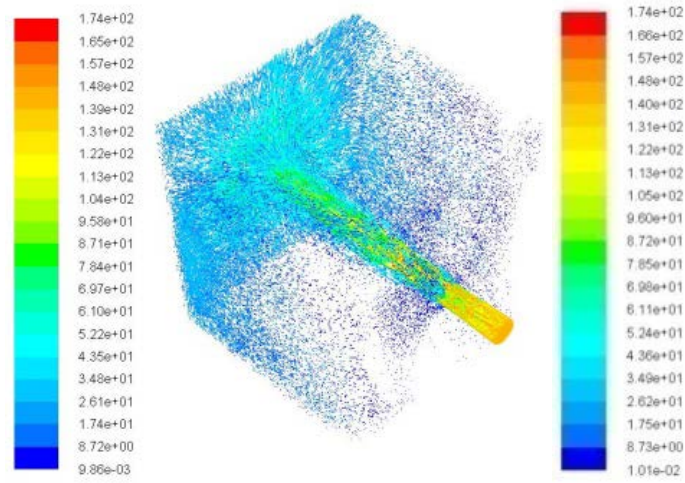

(a)

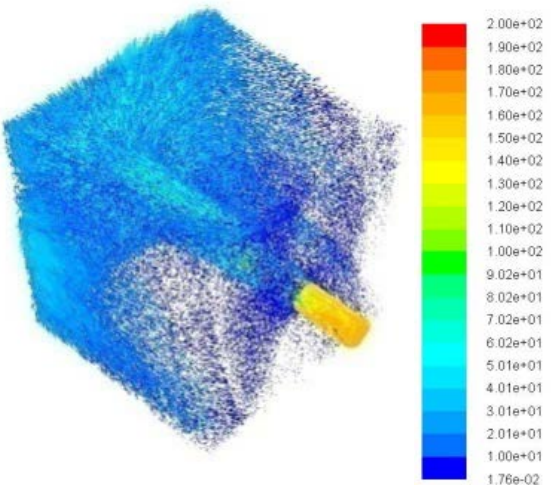

(b)

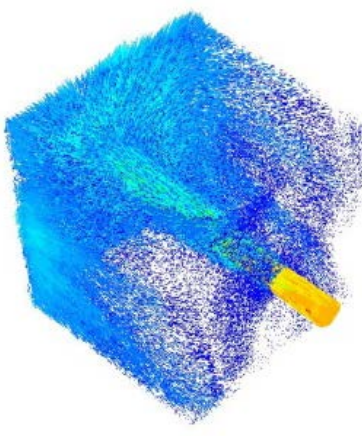

(c)

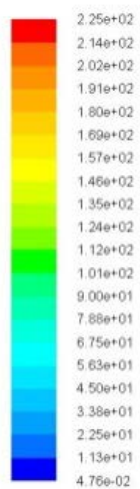

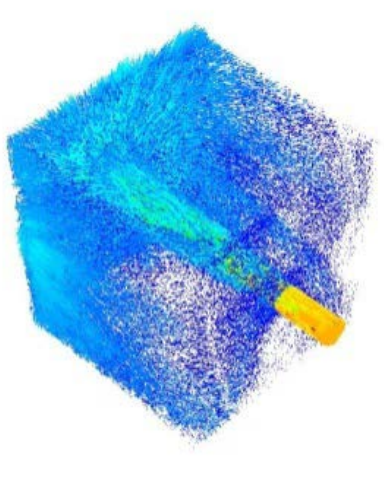

(d)

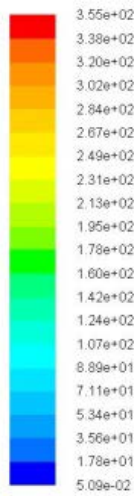

$(200.02$

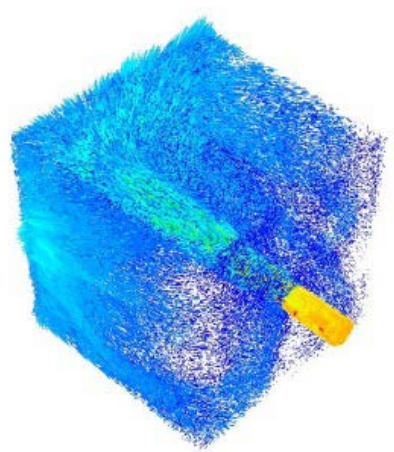

(e)

Figure 4. Velocity of two-phase flow (gas-liquid) of high speed jet under different input velocity. (a) $\mathrm{v}=114.1 \mathrm{~m} / \mathrm{s} ;(\mathrm{b}) \mathrm{v}=142.4$ $\mathrm{m} / \mathrm{s} ;(\mathrm{c}) \mathrm{v}=165.6 \mathrm{~m} / \mathrm{s} ;(\mathrm{d}) \mathrm{v}=186.2 \mathrm{~m} / \mathrm{s} ;(\mathrm{e}) \mathrm{v}=286.9 \mathrm{~m} / \mathrm{s}$.

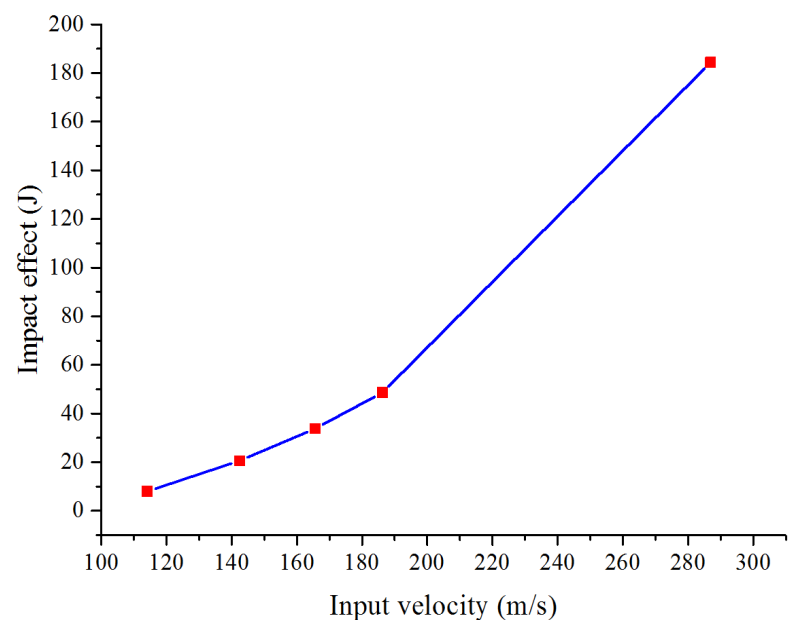

Figure 5. Impact effect of high speed jet under different input velocity.

following conclusions are summarized:

1) Although there is no loss of the input velocity in the spray nozzle, it is notable that the impact velocity of high speed jet decreases swiftly after the liquid flows in. In addition, the maximum impact velocity is at the entrance of the noz- 
zle.

2) As the input velocity increases, the velocity of two-phase flow (gas-liquid) of high speed jet soars.

3) It is obvious the impact effect on the device shows exponential growth with the rise in input velocity.

\section{Acknowledgements}

The researchers would like to graciously thank the National Natural Science Foundation of China (Project no.31601397) and Hainan Natural Science Foundation (Project no. 20163113).

\section{Conflicts of Interest}

The authors declare no conflicts of interest regarding the publication of this paper.

\section{References}

[1] Tu, Z.C., Yin, Y.B., Wang, H., Liu, G.X., Chen, L.L., Zhang, P., et al. (2013) Effect of Dynamic High-Pressure Microfluidization on the Morphology Characteristics and Physicochemical Properties of Maize Amylose. Starch/Starke, 65, 390-397. https://doi.org/10.1002/star.201200120

[2] Liu, P.L., Hu, X.S. and Shen, Q. (2010) Effect of High Hydrostatic Pressure on Starches: A Review. Starch/Starke, 62, 615-628.

https://doi.org/10.1002/star.201000001

[3] Soon, S.Y., Harbidge, J., Titchener-Hooker, N.J. and Shamlou, P.A. (2001) Prediction of Drop Breakage in an Ultra-High Velocity Jet Homogenizer. Journal of Chemical Engineering of Japan, 34, 640-646. https://doi.org/10.1252/jcej.34.640

[4] Fua, Z., Luo, S.J., BeMillerb, J.N., Liu, W. and Liu, C.M. (2015) Effect of High-speed Jet on Flow Behavior, Retrogradation, and Molecular Weight of Rice Starch. Carbohydrate Polymers, 133, 61-66. https://doi.org/10.1016/j.carbpol.2015.07.006

[5] Xia, W., Wang, F., Li, J.H., Wei, X.Y., Fu, T.K., Cui, L.H., et al. (2015) Effect of High Speed Jet on the Physical Properties of Tapioca Starch. Food Hydrocolloids, 49, 35-41. https://doi.org/10.1016/j.foodhyd.2015.03.010

[6] Fu, Z., Luo, S.J., BeMiller, J., Liu, N.W. and Liu, C.M. (2015) Influence of High-Speed Jet on Solubility, Rheological Properties, Morphology and Crystalline Structure of Rice Starch. Starch/Starke, 67, 1-9. https://doi.org/10.1002/star.201400256

[7] Guo, Z.Y., Fletcher, D.F. and Haynes, B.S. (2015) Implementation of a Height Function Method to Alleviate Spurious Currents in CFD Modeling of Annular Flow in Micro Channels. Applied Mathematical Modelling, 39, 4665-4686. https://doi.org/10.1016/j.apm.2015.04.022

[8] Gong, J., Xia, W., Li, J.H. and Wei, X.Y. (2017) Computational Fluid Dynamics Simulation of High Speed Jet under Different Input Pressures. International Journal of High Energy Physics, 4, 12-18. https://doi.org/10.11648/j.ijhep.20170401.12

[9] Liu, H.B., Li, P.Y., Xiao, H.N. and Mu, W.T. (2015) The Fluid-Solid Coupling Analysis of Screw Conveyor in Drilling Fluid Centrifuge Based on ANSYS. Petroleum, 1, 221-226. https://doi.org/10.1016/j.petlm.2015.07.009 
[10] Farkasll. T. and Tóth (2010) Fluent Analysis of a ROSA Cold Leg Stratification Test. Nuclear Engineering and Design, 240, 2169-2175. https://doi.org/10.1016/j.nucengdes.2009.11.025

[11] Rybdylovaa, O., Poultona, L., Qubeissib, M.A., Elwardanyc, A.E., Cruaa, C., Khanad, T., et al. (2018) A Model for Multi-Component Droplet Heating and Evaporation and Its Implementation into ANSYS Fluent. International Communications in Heat and Mass Transfer, 90, 29-33.

https://doi.org/10.1016/j.icheatmasstransfer.2017.10.018

[12] Popovici, C.G. (2017) HVAC System Functionality Simulation Using ANSYS-Fluent. Energy Procedia, 112, 360-365. https://doi.org/10.1016/j.egypro.2017.03.1067

[13] Kirpo, M. (2013) Global Simulation of the Czochralski Silicon Crystal Growth in ANSYS FLUENT. Journal of Crystal Growth, 371, 60-69.

https://doi.org/10.1016/j.jcrysgro.2013.02.005

[14] Hosseini, S.A. and Tafreshi, H.V. (2012) Modeling Particle-Loaded Single Fiber Efficiency and Fiber Drag Using ANSYS-Fluent CFD Code. Computers \& Fluids, 66, 157-166. https://doi.org/10.1016/j.compfluid.2012.06.017 